\title{
PIK3CA mutation confers resistance to chemotherapy in triple-negative breast cancer by inhibiting apoptosis and activating the $\mathrm{PI} 3 \mathrm{~K} / \mathrm{AKT} / \mathrm{mTOR}$ signaling pathway
}

\author{
Huayu Hu ${ }^{1,2}$, Junyong Zhu ${ }^{2,3}$, Yuting Zhong ${ }^{2,3}$, Rui Geng ${ }^{2,3}$, Yashuang Ji ${ }^{1,2}$, Qingyu Guan ${ }^{1,2}$, \\ Chenyan Hong ${ }^{1,2}$, Yufan $\mathrm{Wei}^{1,2}$, Ningning Min ${ }^{1,2}$, Aiying $\mathrm{Qi}^{2}$, Yanjun Zhang ${ }^{2}$, Xiru $\mathrm{Li}^{2}$ \\ ${ }^{1}$ School of Medicine, Nankai University, Tianjin, China; ${ }^{2}$ Department of General Surgery, Chinese People's Liberation Army General Hospital, \\ Beijing, China; ${ }^{3}$ Medical School of Chinese PLA, Beijing, China \\ Contributions: (I) Conception and design: X Li, Y Zhang, A Qi; (II) Administrative support: X Li; (III) Provision of study materials or patients: X Li; \\ (IV) Collection and assembly of data: All authors; (V) Data analysis and interpretation: All authors; (VI) Manuscript writing: All authors; (VII) Final \\ approval of manuscript: All authors. \\ Correspondence to: Xiru Li; Yanjun Zhang; Aiying Qi. Department of General Surgery, Chinese People's Liberation Army General Hospital, Beijing \\ 100853, China. Email: 2468li@sina.com; zhangyanjun301@163.com; qiay79@163.com.
}

Background: Triple-negative breast cancer (TNBC) is a malignant subtype of breast cancer, the main treatments for which are chemotherapy and surgery. PIK3CA is an oncogene that encodes the p110 $\alpha$ subunit of class IA PI3K to regulate cell proliferation and apoptosis. Some reports have observed neoadjuvant chemotherapy (NAC) to have poor pathological complete response (pCR) rates in TNBC with PIK3CA mutation. This study aimed to explore the mechanism of how mutant PIK3CA alters chemotherapeutic susceptibility in TNBC.

Methods: TNBC cell lines (MDA-MB-231 and MDA-MB-468) with PIK3CA gene mutations (E545K and H1047R regions) and overexpression were established by transfection. NOD/SCID mice were used for in vivo experiments. Epirubicin was used as the chemotherapeutic agent. Cell viability, cell cycle, apoptosis, and Transwell assays were conducted for phenotype analysis. Western blot, quantitative reverse transcriptionpolymerase chain reaction, and immunohistochemistry were used to detect gene and protein expression levels. A clinical analysis of 50 patients with TNBC was also performed.

Results: Cell viability and Transwell assays showed that PIK3CA mutation promoted TNBC cell growth and conferred an enhanced migratory phenotype. Cell cycle and apoptosis assays showed that PIK3CA mutation moderately improved the proliferation ability of TNBC cells and remarkably inhibited their apoptosis. After epirubicin therapy, the proportion of early apoptotic cells decreased among cells with PIK3CA mutation. Further, xenograft tumors grew faster in NOD/SCID mice injected with mutated cell lines than in control group, suggesting that PIK3CA mutation caused chemotherapy resistance. Importantly, western blot and immunohistochemical analysis showed that cells and mouse tumors in the PIK3CA mutation groups exhibited different expression levels of apoptosis-related markers (Xiap, Bcl-2, and Caspase 3) and proteins associated with the PI3K/AKT/mTOR pathway (p110 $\alpha$, AKT, p-AKT, mTOR, p-mTOR, p-4E-BP1, p-p70S6K, and Pten). Moreover, prognostic analysis of 50 patients with TNBC indicated that PIK3CA mutation might be linked with relapse and death.

Conclusions: PIK3CA mutation confers resistance to chemotherapy in TNBC by inhibiting apoptosis and activating the PI3K/AKT/mTOR signaling pathway.

Keywords: Triple-negative breast cancer (TNBC); PIK3CA mutation; apoptosis; PI3K/AKT/mTOR pathway; chemotherapy resistance

Submitted Feb 10, 2021. Accepted for publication Mar 05, 2021.

doi: 10.21037/atm-21-698

View this article at: http://dx.doi.org/10.21037/atm-21-698 


\section{Introduction}

Breast cancer (BC) is the most frequently diagnosed malignancy and the leading cause of cancer death among females globally (1). Triple-negative BC (TNBC), which is characterized by a lack of estrogen receptor (ER), progesterone receptor (PR), and human epidermal growth factor 2 (HER2) expression, accounts for 10-20\% of all $\mathrm{BCs}$ and has a poor prognosis relative to other BC subtypes (2). However, no targeted agents for TNBC currently exist, and the combination chemotherapy of anthracycline and paclitaxel is still the cornerstone of treatment for these problematic tumors. There is a consensus that patients with the TNBC subtype are more likely to benefit from neoadjuvant chemotherapy (NAC) than patients with other subtypes (3). Pathological complete response (pCR) is defined as the pathological disappearance of all target tumor lesions after NAC (4). Although $20 \%$ of TNBC patients attain a pCR after initial NAC, chemotherapy resistance commonly occurs and is responsible for most cases of treatment failure, leading to disease reoccurrence and metastasis (5). Therefore, exploring the mechanisms of resistance to these cytotoxic agents and finding new biomarkers are of high priority in TNBC research.

The phosphatidylinositol 3-kinase/protein kinase B/ mammalian target of the rapamycin (PI3K/AKT/mTOR) signaling pathway plays a crucial role in regulating cellular functions, including cell proliferation, survival, and death (6). PI3Ks are lipid kinases that can be classified into three isozymes (I-III) with different structures and functions. Class I PI3K is a common focus of study in lots of fields and can be divided into class IA and IB. Class IA PI3K is a heterodimer comprising two subunits: a catalytic subunit (p110) and a regulatory subunit (p85). The phosphatidylinositol-4-5-bisphosphate3 -kinase catalytic subunit- $\alpha$ (PIK3CA) gene encodes the $\mathrm{p} 110 \alpha$ subunit of class IA PI3K to phosphorylate phosphatidylinositol-4,5-bisphosphate (PIP2) and converts it to phosphoinositide 3,4,5 trisphosphate (PIP3), and then activates more downstream pathways. Mutations in PIK3CA induce sustained activation of AKT through the $\mathrm{PI} 3 \mathrm{~K} / \mathrm{AKT} / \mathrm{mTOR}$ pathway, reducing the dependence of cells on growth factors, leading to cell growth and transformation (7). As an oncogene, PIK3CA mutation is associated with the occurrence and progression of various cancers and is detected in $20-40 \%$ of BCs $(8-10)$. Significantly, $80-90 \%$ of PIK3CA mutations are located in two hotspots: E542K/E545K (helix region) in exon 9 and H1047R (kinase region) in exon 20 (11).

Compared to hormone receptor (HR)+/HER2- (42\%) BCs and HER2+ (31\%) BCs, TNBCs exhibit a lower PIK3CA mutation rate $(16 \%)(10,12)$. The impact of PIK3CA mutation has been lucubrated in HR+ and HER2+ $\mathrm{BCs}$, but it is not well characterized in TNBC. Some studies have reported that PIK3CA mutation contributes to the resistance of HR+/HER2- BCs to endocrine therapy and HER2+ BCs to anti-HER2 therapy $(13,14)$. Due to the different results produced by limited studies, evaluating patients' survival with TNBC with or without PIK3CA mutation is controversial (15-18). Some previous studies reported that PIK3CA mutation contributed to a poor pCR rate in TNBC treated with NAC, which suggested the mutation might be linked with chemotherapy resistance (19-21). However, no research has further explored how PIK3CA mutation affects TNBC cell functions and alters their susceptibility to cytotoxic drugs.

In this study, 2 TNBC cell lines (MDA-MB-231 and MDA-MB-468, PIK3CA wild type) were used to establish cells with PIK3CA mutation and mice xenograft models. The role of PIK3CA mutation and the molecule mechanism of chemotherapy resistance in TNBC were explored and identified in vivo and in vitro. Meanwhile, tumor tissue specimens from 50 patients with TNBC were selected for gene sequencing and immunohistochemical analysis, and the patients' follow-up data were also collected for prognostic analysis. We present the following article following the ARRIVE reporting checklist (available at http://dx.doi.org/10.21037/atm-21-698).

\section{Methods}

\section{Cell culture}

The human TNBC cell lines MDA-MB-231 and MDAMB-468 (PIK3CA wild-type) were obtained from the American Type Culture Collection (ATCC). MCF-7 cell lines were not used due to containing a mutation in the PIK3CA gene. MDA-MB-231 cells were cultured in Dulbecco's Modified Eagle Medium (DMEM) (Biological Industries), and MDA-MB-468 cells were cultured in L15 (Gibco) media. The cell cultures were supplemented with $10 \%$ fetal bovine serum (FBS) (Biological Industries) and $1 \%$ penicillin/streptomycin (Biological Industries). The cells were incubated at $37^{\circ} \mathrm{C}$ with $5 \% \mathrm{CO}_{2}$ in the air and used at low passage $(<15)$ after thawing. 


\section{Transfection and generation of stable cell lines}

E545K and H1047R are two mutation hotspot regions in the PIK3CA gene, and they have been commonly used in previous studies. Therefore, the following cell groups were constructed in both MDA-MB-231 and MDA-MB-468 cells: control (PIK3 $\left.\mathrm{CA}^{\mathrm{ctrl}}\right)$, overexpression $\left(\mathrm{PIK} \mathrm{CA}^{\mathrm{Oe}}\right)$, mutation of E545K (PIK3 $\mathrm{CA}^{\mathrm{E} 545 \mathrm{~K}}$ ), and mutation of H1047R (PIK3CA ${ }^{\mathrm{H} 1047 \mathrm{R}}$ ). Cells were cultured to $60-70 \%$ confluency in a 6-well plate. Then, cells were transfected with lentiviruses carrying the corresponding target gene purchased from GeneChem. Lentivirus carrying only a green fluorescent protein (GFP) sequence was transfected into cells as a control group. Other sequences are listed in Table S1. Lipofectamine 3000 (Invitrogen) was used to complete the transfection according to the manufacturer's protocol. After 72 hours, a microscope was used to observe the transfection efficiency, following which the cells were isolated and analyzed by flow cytometry (Figure S1A,B,C).

\section{Cell viability analysis}

Cell Counting Kit-8 (CCK-8) assay was used to detect cell proliferation. All the cell lines were seeded on 96-well plates at a density of $5 \times 10^{5} / \mathrm{mL}$. Following attachment, the CCK8 agent (Dojindo Molecular Technologies) was added to MDA-MB-231 cells after 12, 24, 36, 48, 60, and 72 hours. Since the growth of MDA-MB-468 cells was inferior to that of MDA-MB-231 cells, CCK- 8 agent was added to MDA-MB-468 cells after 24, 48, 72, 96, and 120 hours. A microplate reader (Bio-Rad) was used to measure the optical density (OD) at a wavelength of $450 \mathrm{~nm}$. Growth curves were plotted to examine the proliferation condition of cells according to the absorbance.

\section{Cell cycle analysis}

MDA-MB-231 and MDA-MB-468 cells were cultured in 6-well plates and washed with $1 \mathrm{~mL}$ phosphate-buffered saline (PBS) at $4{ }^{\circ} \mathrm{C}$. Then, the cells were fixed in $75 \%$ ethanol at $4{ }^{\circ} \mathrm{C}$ overnight. The mixture was supplemented with $500 \mu \mathrm{L}$ PBS containing $50 \mu \mathrm{g} / \mathrm{mL}$ RNase A and $50 \mu \mathrm{g} / \mathrm{mL}$ propidium iodide. After 30 minutes of incubation without exposure to light, the cell cycle distribution was analyzed by flow cytometry.

\section{Apoptosis assays}

Cells were collected, washed with $2 \mathrm{~mL}$ PBS, digested with
trypsin-EDTA, and then transferred to the corresponding tubes. The additions of $5 \mu \mathrm{L}$ APC-Annexin $\mathrm{V}$ and $5 \mu \mathrm{L} 7$-amino-actinomycin $\mathrm{D}(7$-AAD) were made to the cell suspension, and the cells were left to stain for 15-20 minutes at room temperature in the dark. Finally, flow cytometry was used to assess cell apoptosis by calculating the numbers of early and late apoptotic cells.

\section{Transwell migration assays}

Transwell migration assays were conducted using a 24-well plate ( $8 \mathrm{~m}$ pore size) (Millipore). MDA-MB-231 and MDA-MB-468 cells $\left(5 \times 10^{5} / \mathrm{mL}\right)$ were added to the Transwell plates' upper chamber in $200 \mu \mathrm{L}$ of DMEM with $1 \%$ FBS. The lower chamber contained a $500 \mu \mathrm{L}$ DMEM culture medium supplemented with $10 \%$ FBS. The plates with MDA-MB-231 cells and MDA-MB-468 cells were incubated for 6 and 20 hours, respectively, at $37^{\circ} \mathrm{C}$ in $5 \%$ $\mathrm{CO}_{2}$ in the air. Then, a cotton-tipped swab was used to remove the residual cells in the upper chamber carefully. Cells that had migrated to the lower chamber were fixed and stained with crystal violet for 15 minutes. A microscope was used to observe and count the migrated cells.

\section{Cell treatment}

Epirubicin is an epimer of doxorubicin that is generally used as a chemotherapeutic agent to treat both early and metastatic BC (22). Therefore, it was selected to investigate the chemotherapy sensitivity of TNBC cells in this study. Epirubicin was purchased from Pfizer Inc. A cellular drug resistance assay determined the drug susceptivity of each cell line. Cell viability was measured under different epirubicin concentrations using CCK-8 assays (Figure S1D), and the half-maximal inhibitory concentration $\left(\mathrm{IC}_{50}\right)$ for each cell group is listed in the Table S2. Then, cells were treated with epirubicin at a concentration close to their $\mathrm{IC}_{50}$ value $(1.5 \mu \mathrm{mol} / \mathrm{L}$ for MDA-MB-231 and $0.5 \mu \mathrm{mol} / \mathrm{L}$ for MDA-MB-468) and used for western blot and apoptotic assay.

\section{Animal experiments}

Four groups of transfected MDA-MB-231 cells (PIK3CA ${ }^{\mathrm{Oe}}$, PIK3CA ${ }^{\mathrm{E} 545 \mathrm{~K}}$, PIK3CA ${ }^{\mathrm{H} 1047 \mathrm{R}}$, and PIK3CA $\left.{ }^{\mathrm{ctrl}}\right)$ were cultured and prepared at a density of $2 \times 10^{7} / \mathrm{mL}$. Sixty-four 6-weekold female non-obese diabetic-severe/combined immunedeficiency (NOD/SCID) mice were purchased from 
Charles River Laboratories and kept in an animal house located at the Experimental Animal Center of Chinese PLA General Hospital. The mice were kept at a room temperature of $20 \pm 2{ }^{\circ} \mathrm{C}$ and a 12-hour light/dark cycle, with 4 mice in each cage. They were randomly divided into four groups ( $\mathrm{n}=16$ in each group) and subcutaneously injected in the mammary fat pad with $100 \mu \mathrm{L}$ of the corresponding cells. Ten days after the injection, the tumors were palpable, and the volumes were measured twice a week with a vernier caliper (length $\times$ width $^{2} \times 1 / 2=$ volume). After the tumors had reached $200 \mathrm{~mm}^{3}$, the mice were treated with epirubicin $(10 \mathrm{mg} / \mathrm{kg}$, i.p. once a week, 3 times in total). Ten days after the final treatment, the tumors were harvested and weighted. Animal experiments were performed under a project license (no. S2016-023-01) granted by the Ethics Committee of Chinese PLA General Hospital. All animal experiments complied with the National Institutes of Health Guide for the Care and Use of Laboratory Animals.

\section{Western blot}

Cells or tumor tissues were lysed with RIPA buffer for 30 minutes on ice. Proteins were separated by sodium dodecyl sulfate-polyacrylamide gel electrophoresis (SDSPAGE) on a $10 \%$ gel and then transferred to nitrocellulose membranes. The membranes were blocked with $5 \%$ FBS for 1 hour at room temperature, incubated with primary antibodies (listed in Table S3) overnight at $4{ }^{\circ} \mathrm{C}$, and then incubated with secondary antibodies $(1: 5,000)$ for 1 hour at room temperature. The proteins were visualized using an enhanced chemiluminescence reagent.

\section{Quantitative reverse transcription-polymerase chain reaction}

Total RNA was extracted from tumor tissues with TRIzol reagent (Sigma). Then, messenger RNA (mRNA) was transcribed to complementary DNA (cDNA) using a Transcript First-Stand cDNA Synthesis Kit (TaKaRa). According to the manufacturer's protocol, polymerase chain reaction (PCR) was performed on a CFX96 Real-time System (BIO-RAD). The primer sequences are listed in Table S4.

\section{Immunobistochemistry}

Tumor tissues were dehydrated and embedded in paraffin.
Then the embedded tissues were cut into sections of every 5 - $\mu$-thick tissue slice. The 5 - $\mu \mathrm{m}$ paraffin sections were deparaffinized and washed with water. Then, antigen retrieval was conducted, and endogenous peroxidase was removed. The tissue sections were blocked with $5 \%$ goat serum, after which primary antibodies (Invitrogen) were added dropwise. After incubation at $4{ }^{\circ} \mathrm{C}$ overnight, the sections were washed with PBS; then, secondary antibodies were added, and the sections were incubated for 2 hours at room temperature. Next, the tissue sections were washed 3 times with PBS before being incubated with horseradish peroxidase-biotin conjugate for 1 hour at room temperature. After washing, the DAB agent was added for 1 minute and then washed away. Finally, hematoxylin was used for counterstaining, and the sections were observed under a microscope after dehydration.

\section{Patients and specimens}

From January 2014 to December 2016, 60 female patients who were diagnosed as TNBC, underwent surgery excision, and completed standard chemotherapy in Chinese PLA General Hospital were selected. After the exclusion of 10 patients due to failure to follow up, 50 patients were finally included. Clinical data were acquired from the patients' medical records, and follow-up information was obtained by telephone or death certificate. Tumor specimens of all 50 patients were obtained for gene sequencing to detect PIK3CA mutations (Genechem Incorporation), and some were collected for immunohistochemical analysis. This study was conducted following the Declaration of Helsinki (as revised in 2013). The Ethics Committee approved the study of Chinese PLA General Hospital (No. S2016023-01), and informed consent was obtained from all the patients.

\section{Statistical analysis}

Data were analyzed by SPSS 23.0, standard version (SPSS Inc., Chicago, IL), and Prism 7.0 (GraphPad Software Inc.). One-way analysis of variance (ANOVA) and Tukey's multiple comparisons test was used to analyze data from western blot, quantitative reverse transcription-PCR (RTqPCR), Transwell migration assay, cell/tumor growth experiments, and flow cytometric analysis among different groups. The t-test was used to analyze patients by age. Other clinicopathological characteristics were analyzed 
using the $\chi^{2}$ test or Fisher's exact test. Each experiment was conducted in triplicate. Data were described as mean \pm standard deviation $(\mathrm{SD}) . \mathrm{P}<0.05$ was considered to show a significant statistical difference.

\section{Results}

PIK3CA mutation promotes growth, inhibits apoptosis, and confers an enhanced migratory phenotype in TNBC cells

We evaluated cell viability in the TNBC cell lines MDAMB-231 and MDA-MB-468 after transfection (PIK3CA ${ }^{\mathrm{Oe}}$, PIK3 $3 A^{\mathrm{E} 545 \mathrm{~K}}$, PIK3 $\mathrm{CA}^{\mathrm{H} 1047 \mathrm{R}}$, and PIK3 $\mathrm{CA}^{\mathrm{ctrl}}$ ) using CCK-8 assays. Among both MDA-MB-231 and MDAMB-468 cells, cells in the PIK3CA ${ }^{\mathrm{Oe}}, \mathrm{PIK} 3 \mathrm{CA}^{\mathrm{E} 545 \mathrm{~K}}$, and PIK3CA ${ }^{\mathrm{H} 1047 \mathrm{R}}$ groups grew faster in number than PIK3 $\mathrm{CA}^{\text {ctrl }}$ cells (Figure 1A). To identify whether the PIK3CA mutation promoted proliferation or inhibited apoptosis in TNBC cells, propidium iodide staining was used to study the cell cycle. As the results showed (Figure 1B,C), PIK3CA mutation increased the proportion of MDA-MB-231 cells in the $\mathrm{S}$ phase moderately but not significantly, except for the PIK3CA ${ }^{\mathrm{Oe}}$ group $(\mathrm{P}=0.0473)$. In the MDA-MB-468 cells, no significant difference was seen between the PIK3CA ${ }^{\text {ctrl }}$ cells and the other 3 groups, indicating that PIK3CA mutation might not remarkably improve the proliferation ability of TNBC cells. Subsequently, APC-Annexin V and 7 -AAD staining was carried out for apoptosis analysis. The results showed that the proportion of early apoptotic cells in the PIK3CA mutation (PIK3CA ${ }^{\mathrm{E} 545 \mathrm{~K}} / \mathrm{PIK} 3 \mathrm{CA}^{\mathrm{H} 1047 \mathrm{R}}$ ) groups and the PIK3 $3 \mathrm{CA}^{\mathrm{Oe}}$ group decreased significantly in both MDA-MB-231 and MDA-MB-468 cells (Figure 1D,E). This observation implied that PIK3CA mutation predominantly inhibited TNBC cell apoptosis. Finally, to investigate the migration and invasion of TNBC cells with PIK3CA mutation, Transwell migration assays were performed. As shown in Figure $1 F$ and $G$, among MDA-MB-231 cells, those carrying mutation or overexpression of the PIK $3 \mathrm{CA}$ gene displayed enhanced aggressiveness compared with PIK3CA ${ }^{\text {ctrl }}$ cells $(\mathrm{P}<0.0001)$. In MDA-MB-468 cells, significant differences were found in the PIK $3 \mathrm{CA}^{\mathrm{Oe}}$ and PIK3CA ${ }^{\mathrm{H} 1047 \mathrm{R}}$ groups compared to the PIK3 $\mathrm{CA}^{\mathrm{ctrl}}$ group $(\mathrm{P}<0.0001$ and $\mathrm{P}<0.01)$; however, a similar result was not observed for the PIK3 $\mathrm{CA}^{\mathrm{E} 545 \mathrm{~K}}$ group $(\mathrm{P}=0.7162)$. Therefore, it can be concluded that PIK3CA mutation conferred an enhanced migratory phenotype in TNBC cells.

\section{PIK3CA mutation induces resistance to chemotherapy, mainly by inbibiting apoptosis}

The results above inferred that PIK3CA mutation could promote growth and, in particular, inhibit apoptosis in TNBC cell lines. Considering the low pCR rates of NAC in patients with TNBC carrying PIK3CA mutation, more experiments were conducted to explore whether mutated PIK3CA can alter TNBC cells' sensitivity to chemotherapy. As a common chemotherapeutic agent used in BC (22), epirubicin was adopted to treat TNBC cells to observe the response to chemotherapy. The drug susceptivity of each cell line was determined by cellular drug resistance assay, and each $\mathrm{IC}_{50}$ of each cell group is listed in Table $\mathrm{S} 2$. Cell viability assays showed PIK $3 \mathrm{CA}^{\mathrm{Oe}}$, PIK $3 \mathrm{CA}^{\mathrm{E} 545 \mathrm{~K}}$, and PIK3CA ${ }^{\mathrm{H} 1047 \mathrm{R}}$ cells became less sensitive to chemotherapy (Figure S1D). After epirubicin treatment, apoptosis assays were conducted (Figure $2 A, B$ ). The proportion of early apoptotic cells decreased obviously among MDAMB-231 cells carrying PIK3CA mutation. Among the MDA-MB-468 cells, a decrease in the proportions of early apoptotic cells was observed in the PIK3 $3 \mathrm{CA}^{\mathrm{Oe}}$ and PIK3CA ${ }^{\mathrm{E} 545 \mathrm{~K}}$ groups, with the former showing a significant difference $(\mathrm{P}=0.0442)$. An increasing trend of apoptosis was seen in the $\mathrm{PIK} 3 \mathrm{CA}^{\mathrm{H} 1047 \mathrm{R}}$ group, although the $\mathrm{P}$ value was not meaningful $(\mathrm{P}=0.8284)$. Western blot was carried out to detect the protein expression levels in MDA-MB-231 cells. B-cell lymphoma 2 (Bcl-2), X-linked inhibitor of apoptosis protein (Xiap), and Caspase 3 are apoptosis-related proteins; the expression of Xiap and Bcl-2 inhibits apoptosis, while that of Caspase 3 promotes apoptosis. As shown in Figure 2C, after epirubicin treatment, the expression levels of Xiap and $\mathrm{Bcl}-2$ were upregulated in the PIK3 $3 \mathrm{CA}^{\mathrm{Oe}}$, PIK3CA ${ }^{\mathrm{E} 545 \mathrm{~K}}$, and PIK3 $3 \mathrm{CA}^{\mathrm{H} 1047 \mathrm{R}}$ groups compared with the PIK3 $\mathrm{CA}^{\text {crrl }}$ group. These findings suggested PIK3CA mutation inhibited the apoptosis caused by epirubicin.

The following in vivo experimental results further confirmed this conclusion. Four groups of MDAMB-231 cells were subcutaneously implanted into NOD/ SCID mice. When the tumor volume reached $250 \mathrm{~mm}^{3}$, epirubicin was injected intraperitoneally once a week, 3 times in total. No adverse events were observed. The results (Figure 2D) showed that compared with the PIK3CA ${ }^{\text {ctrl }}$ group, the tumor volume in the other 3 groups increased at a significantly faster pace in the sequence of PIK3CA ${ }^{\mathrm{H} 1047 \mathrm{R}}$ PIK3CA ${ }^{\mathrm{E} 54 \mathrm{~K}}$, and PIK3CA ${ }^{\mathrm{Oe}}$. Subsequently, immunohistochemistry demonstrated that mutated PIK3CA 


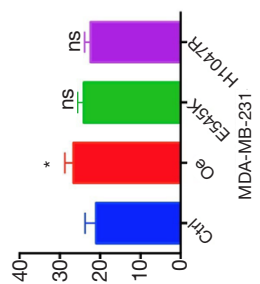

(\%) tuəدxəd әseyd

$\mathrm{s}$ u! uo!̣ıododd s s॥ə弓

$\cup$
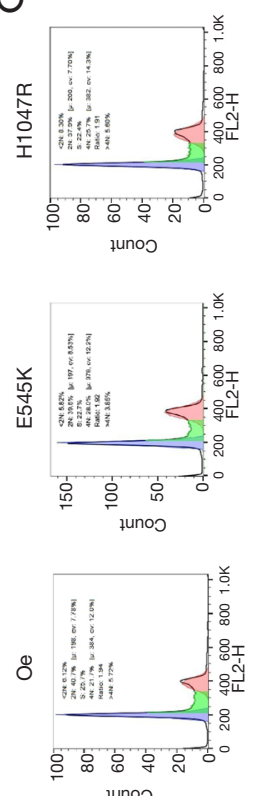

zuno了

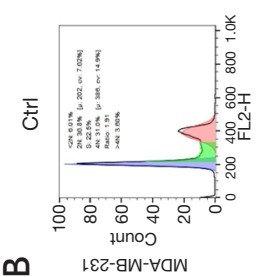

n
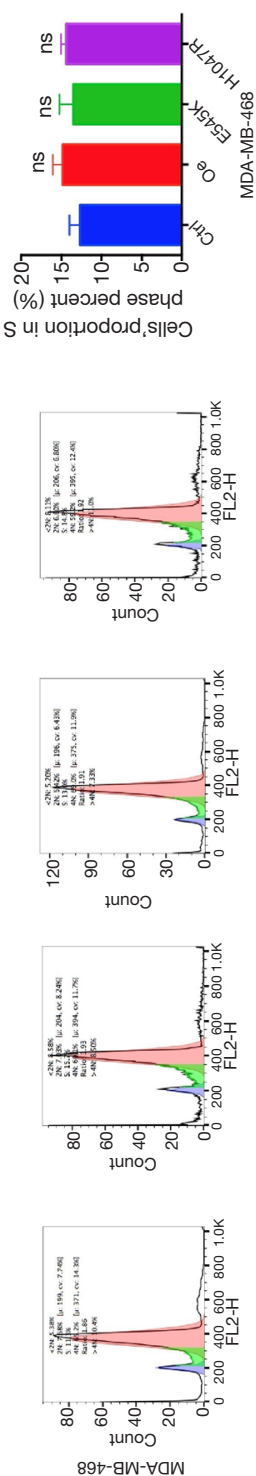

แ
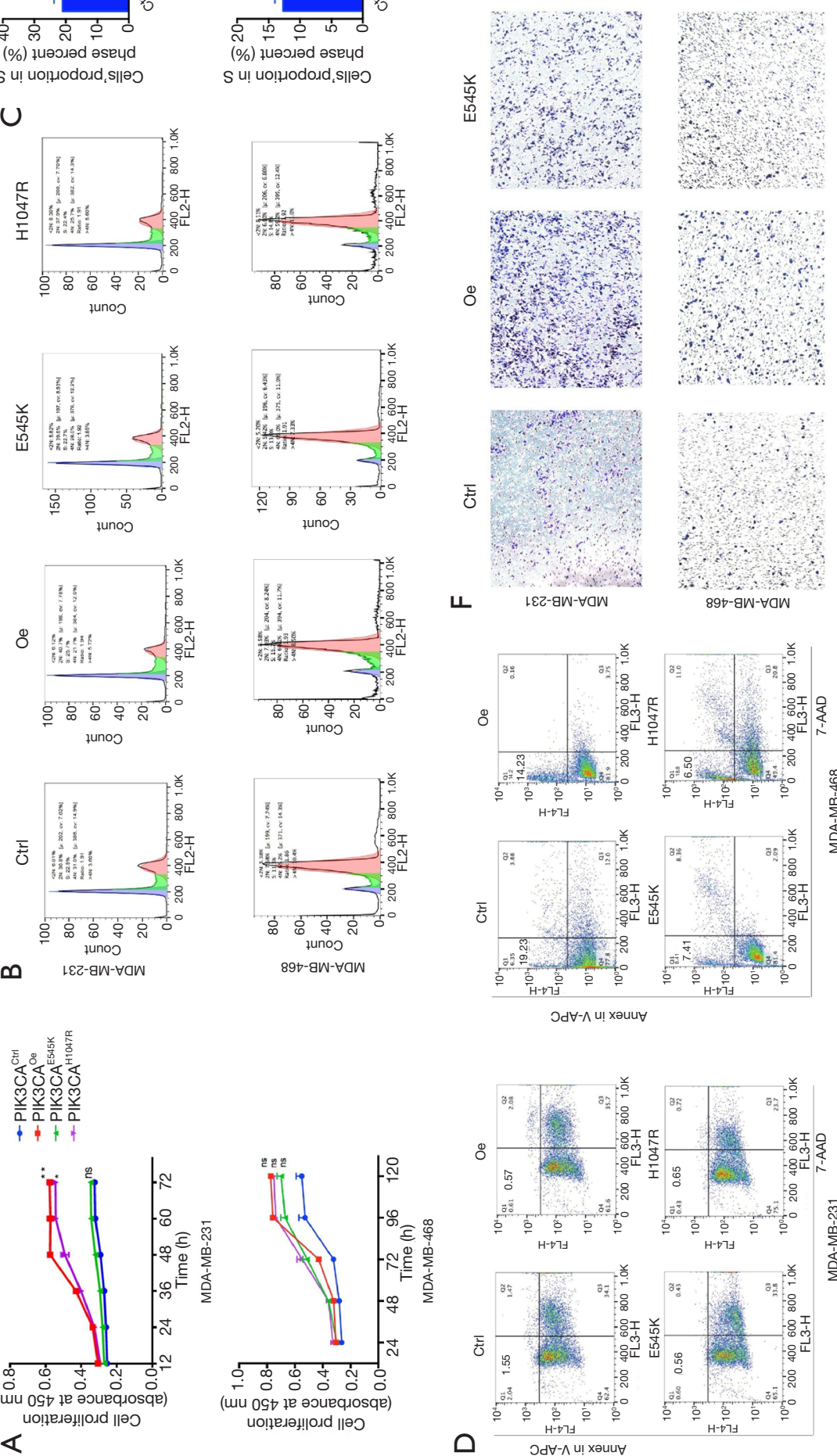
in ${ }^{4}+\cos ^{2}$
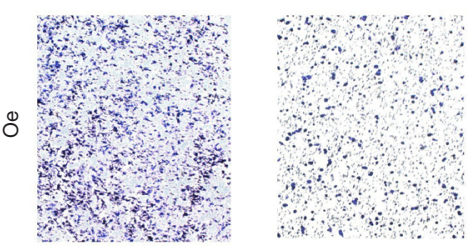

I
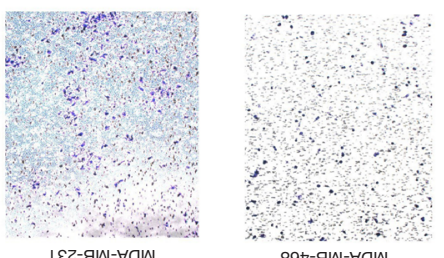

$89 t-9 W-\forall a W$
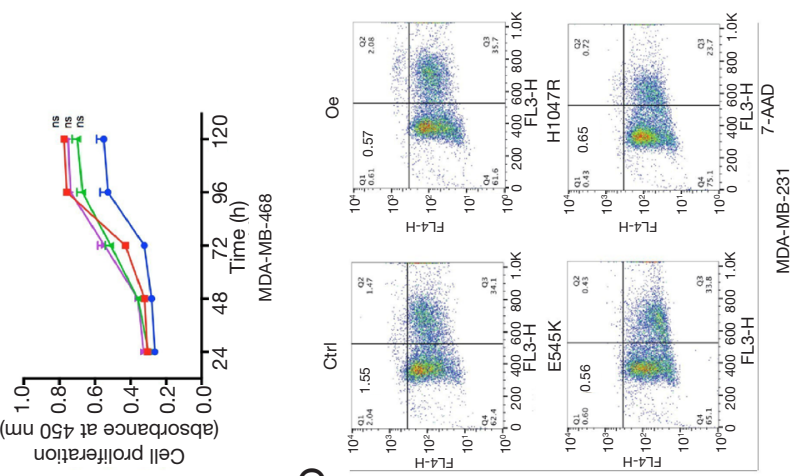
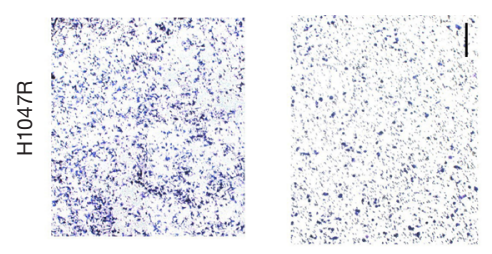

$\cup$
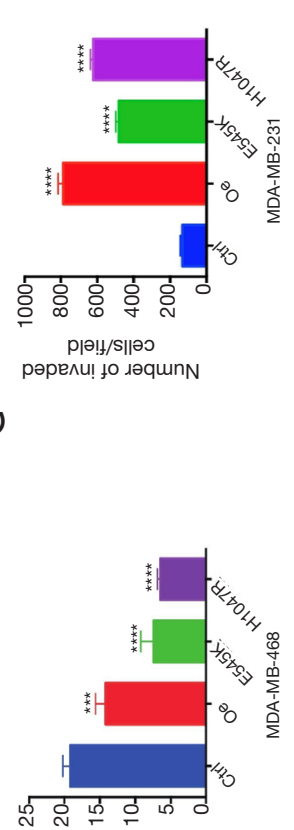

(\%) uo!̣นododd،s॥әว

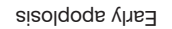

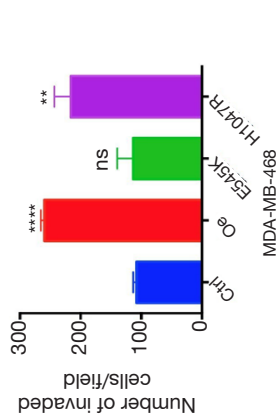

艺

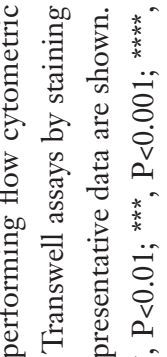

a o o o to

$\overline{\mathrm{y}}$.

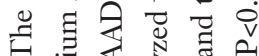

¿

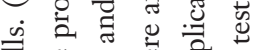

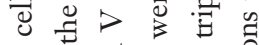

U

乙

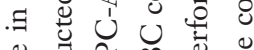

范泀云艺

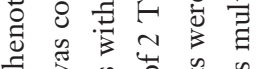

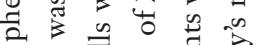

:

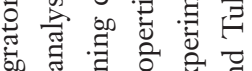

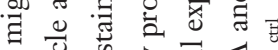

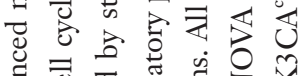

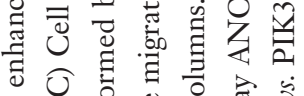

0 0 0

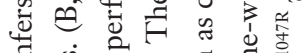

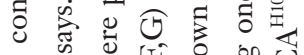

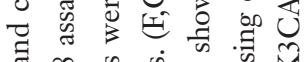

$\omega$

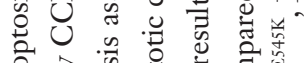

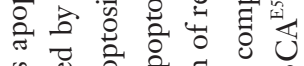

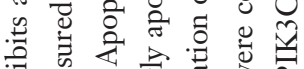

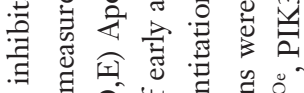

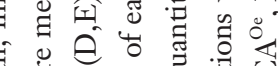

fేّ

क人

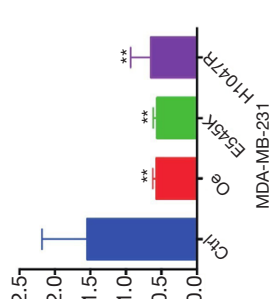

(\%) uo!̣ododd sı|əว

s!soldode К사

ш

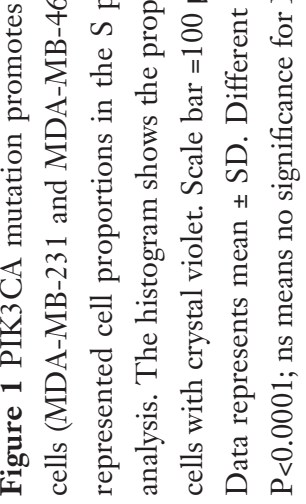


A
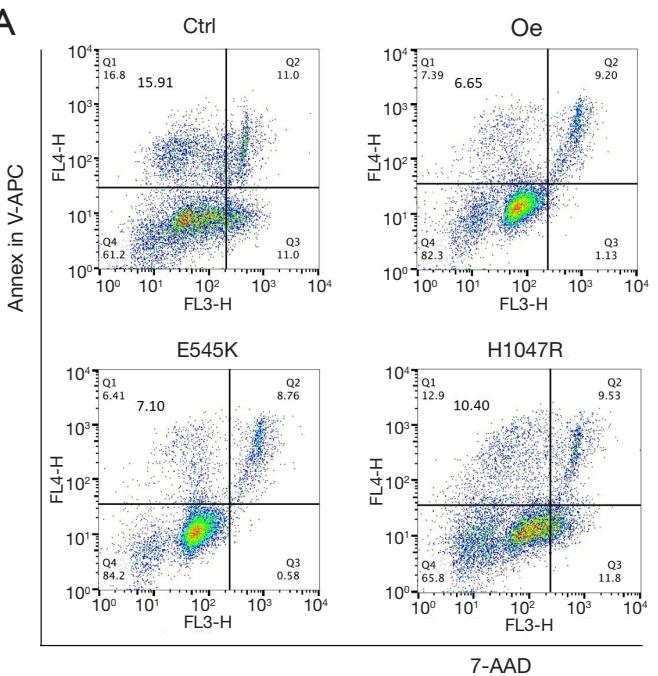

MDA-MB-231

A
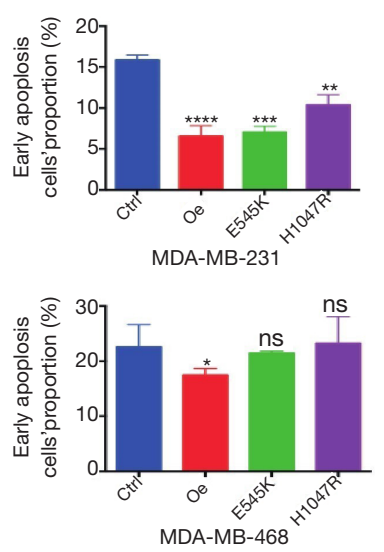

C

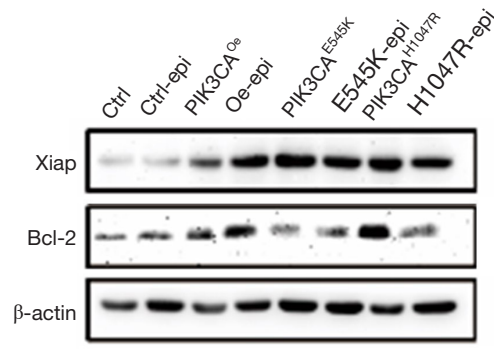

$\mathrm{E}$
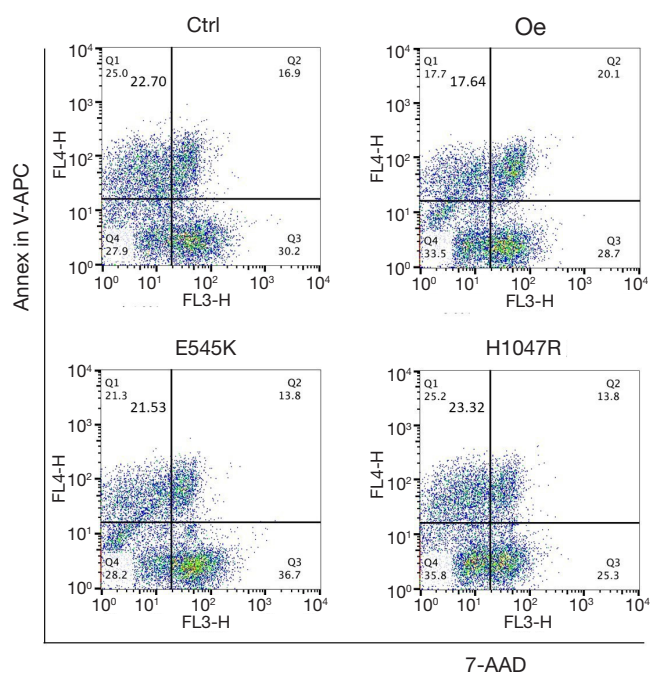

MDA-MB-468

D
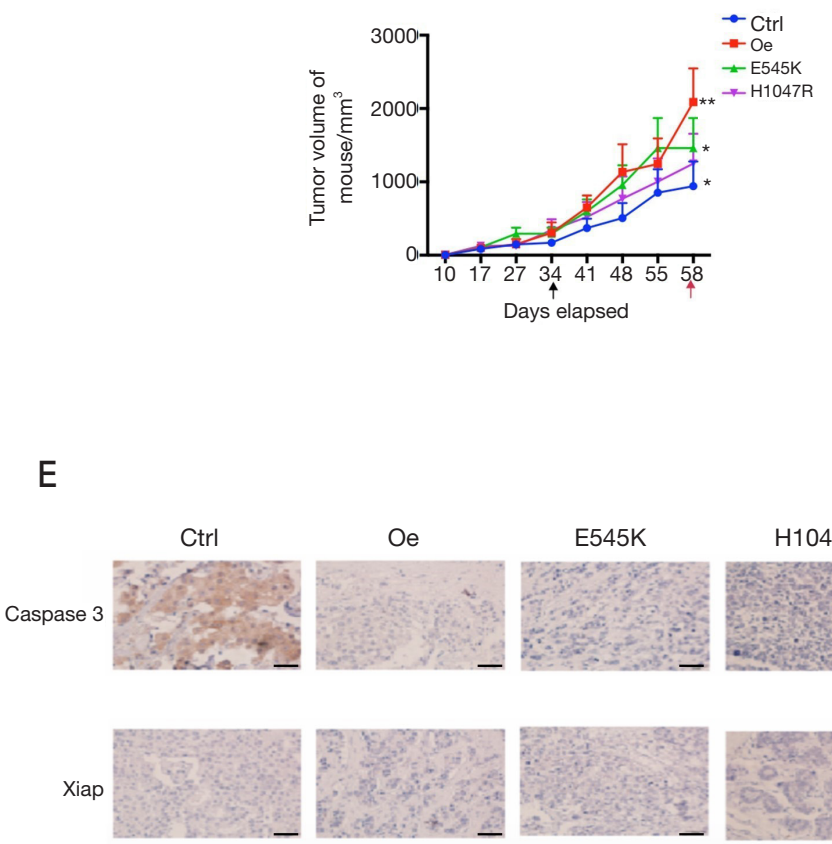

Oe

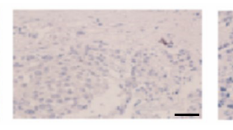

E545K
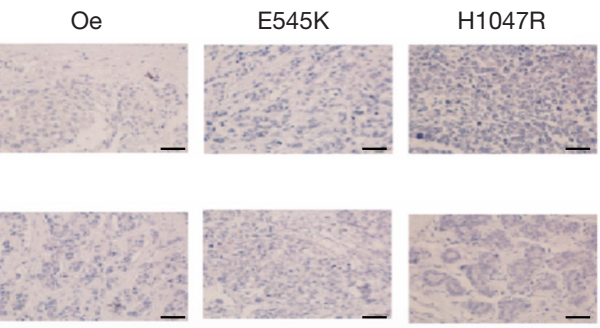

Figure 2 PIK3CA mutation induces resistance to chemotherapy, mainly through inhibiting apoptosis in TNBC cells. (A,B) TNBC cells (MDA-MB-231 and MDA-MB-468) were treated with epirubicin at a concentration close to their $\mathrm{IC}_{50}$ value $(1.5 \mu \mathrm{mol} / \mathrm{L}$ for $\mathrm{MDA}-\mathrm{MB}-231$ cells; $0.5 \mu \mathrm{mol} / \mathrm{L}$ for MDA-MB-468 cells) followed by staining with APC-Annexin V and 7-AAD for flow cytometric analysis. The columns show the proportions of early apoptotic cells. The $\mathrm{IC}_{50}$ value obtained through CCK-8 assays is shown in Figure S1D and Table S2. (C) The expression levels of apoptosis related proteins (Xiap and Bcl-2) in MDA-MB-231 cells treated with epirubicin were detected by western blot. (D) The growth trend of tumor volume in mice treated with epirubicin (10 mg/kg, i.p. once a week, 3 times in total) in different groups. The black arrow represents the first treatment and the red arrow represents tumor extraction. (E) The indicated proteins of tumor tissues of mice were detected by immunohistochemistry. Bar, $50 \mu \mathrm{m}$. Data shown are representative of 3 independent experiments. Data represented mean \pm SD. Different conditions were compared using one-way ANOVA and Tukey's multiple comparisons test. *, $\mathrm{P}<0.05 ;{ }^{* *}, \mathrm{P}<0.01 ;{ }^{* * *}$, $\mathrm{P}<0.001 ;{ }^{* * *} \mathrm{P}<0.0001$; ns means no significance for PIK3CA ${ }^{\mathrm{Oe}}, \mathrm{PIK} \mathrm{CA}^{\mathrm{E} 545 \mathrm{~K}}, \mathrm{PIK} \mathrm{CA}^{\mathrm{H} 1047 \mathrm{R}}$ vs. $\mathrm{PIK} \mathrm{CA}^{\text {ctrl }}$. 
markedly downregulated the expression of Caspase 3 but upregulated the expression of Xiap in tumor tissues (Figure 2E). Combined, these in vitro and in vivo data suggested that PIK3CA mutation attenuated susceptivity and induced resistance to chemotherapy in TNBC cells, mainly through inhibiting apoptosis.

\section{PIK3CA mutation activates the PI3K/AKT/mTOR signaling pathway to confer chemotherapy resistance}

The above results inferred that PIK3CA mutation conferred a phenotype of inhibiting apoptosis from resisting chemotherapy, and the key molecule mechanism leading to this phenotype needed to be identified. The p110 $\alpha$ protein encoded by the PIK3CA gene is the upstream regulator of the $\mathrm{PI} 3 \mathrm{~K} / \mathrm{AKT} / \mathrm{mTOR}$ signaling pathway. Accordingly, we hypothesized that PIK3CA mutation might have an influence on this pathway in TNBC cells. AKT is a downstream protein of PI3K in this pathway. Phosphorylated AKT (p-AKT) activates mTOR, which regulates protein synthesis and cell growth, together with its regulators, such as p70S6 kinase (p70S6K) and 4E-BP1. Pten is a tumor suppressor gene that acts as a negative modulator in the PI3K/AKT/mTOR pathway (23). To confirm our hypothesis, the quantitative expression of proteins related to the $\mathrm{PI} 3 \mathrm{~K} / \mathrm{AKT} / \mathrm{mTOR}$ signaling pathway was verified by western blot and immunohistochemical staining in MDA-MB-231 cells. As shown in Figure 3A, the expression levels of AKT, p-AKT, $\mathrm{mTOR}$, and $\mathrm{p}-\mathrm{mTOR}$ were increased in the PIK3CA mutation $\left(\mathrm{PIK} 3 \mathrm{CA}^{\mathrm{E} 545 \mathrm{~K}} / \mathrm{PIK} 3 \mathrm{CA}^{\mathrm{H} 1047 \mathrm{R}}\right.$ ) and PIK3 $3 \mathrm{CA}^{\mathrm{Oe}}$ groups compared with the PIK3 $\mathrm{CA}^{\text {ctrl }}$ group, indicating that PIK3CA mutation contributed to the activation of the $\mathrm{PI} 3 \mathrm{~K} / \mathrm{AKT} / \mathrm{mTOR}$ pathway.

Meanwhile, proteins were extracted from tumor tissues of mice (Figure 3B). In tumor tissues from the PIK3CA mutation mice, the expression of p110 $\alpha$, p-AKT (Ser 473), mTOR, p-4E-BP1 (Thr37/46), and p-p70S6K (Ser371/ Thr389) was upregulated, while that of Pten was slightly downregulated. Further, RT-qPCR assays were conducted to verify the results at the mRNA level (Figure 3C). Immunohistochemistry (Figure $3 D$ ) revealed that AKT and mTOR protein expression was high in the PIK3CA ${ }^{\mathrm{E} 545 \mathrm{~K}}$ and PIK3 $3 \mathrm{CA}^{\mathrm{H} 1047 \mathrm{R}}$ groups. The expression of Pten was low in PIK $3 \mathrm{CA}^{\mathrm{E} 545 \mathrm{~K}}$ and PIK3 $3 \mathrm{CA}^{\mathrm{H} 1047 \mathrm{R}}$ cells but comparatively high in the PIK3CA ${ }^{\text {ctrl }}$ and PIK3CA ${ }^{\mathrm{Oe}}$ groups. To sum up, an initial conclusion could be drawn that PIK3CA mutation activated the PI3K/AKT/mTOR pathway, presented a phenotype of inhibiting apoptosis, and induced resistance to chemotherapy in TNBC cells.

\section{PIK3CA mutation may be associated with relapse and death in patients with TNBC}

To enable a comparison of the clinicopathological characteristics of patients with PIK3CA-mutated and PIK3CA wild-type TNBC, 50 patients with TNBC were included according to the criteria described in Methods. The median age of the cohort was 54 years (age range, 35 to 75 years). The frequency of PIK3CA mutations was $22 \%(11 / 50)$, and these mutations were mainly located in E $545 \mathrm{~K}$ on exon $9(1 / 50,2 \%)$ and H1047R on exon $20(8 / 50$, $16 \%)$, accounting for $81.8 \%$ of patients carrying PIK3CA mutation. All of the patients had a diagnosis of invasive cancer. These patients' postoperative chemotherapy regimens consisted of AC, TC, and TAC (A for adriamycin, $\mathrm{T}$ for docetaxel, $\mathrm{C}$ for cyclophosphamide). Most of the patients $(38 / 50,76 \%)$ were diagnosed as early BC [tumornode-metastasis (TNM) stage I/II]. The enrolled patients had a median follow-up period of 35.5 months (range, 12 to 47 months). Reoccurrence was observed in 4 patients, and metastasis was reported in 5 cases. Four deaths were recorded. Of the patients, $72 \%(36 / 50)$ had a family history of cancer. The patients' clinicopathological information is displayed in Table 1.

Comparisons of the PIK3CA mutation and PIK3CA wild-type TNBC groups showed that there were no significant differences between the groups in terms of age, tumor size, tumor location, axillary lymph nodes status, histological grade, TNM stage, prognosis, family history, p53 status, or Ki67 status $(\mathrm{P}>0.05)$. However, more negative events were observed in patients with PIK3CA mutation in the form of relapse $(9.1 \%$ vs. $7.7 \%)$ and death $(9.1 \% v s$. $7.7 \%)$. This observation indicated that PIK3CA mutations might be associated with relapse and death in patients with TNBC, and further large-scale study is needed to investigate this potential association.

Also, tumor tissues were collected from the patients with TNBC for immunohistochemical analysis. Compared with the PIK3 $\mathrm{CA}^{\text {ctrl }}$ group, the expression of AKT and mTOR was higher in the PIK3CA groups, while the levels of Pten and Bcl-2 were lower in the PIK3CA ${ }^{\mathrm{H} 1047 \mathrm{R}}$ group and higher in the PIK3 $\mathrm{CA}^{\mathrm{E} 545 \mathrm{~K}}$ group. No significant difference was discovered in Xiap and caspase 3 protein expression 


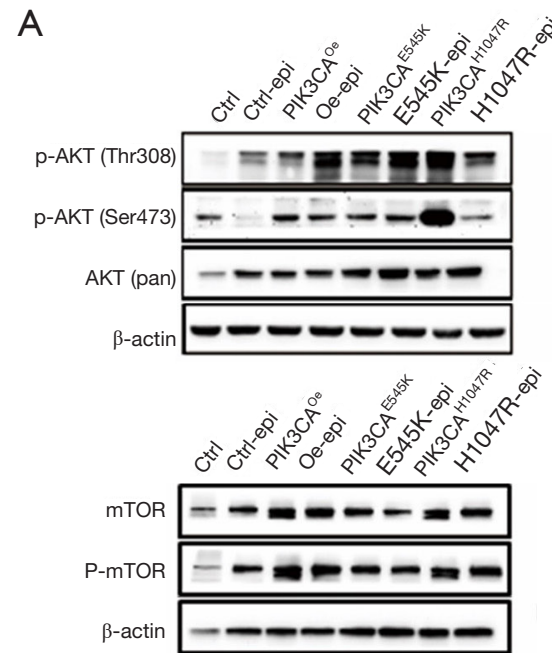

C

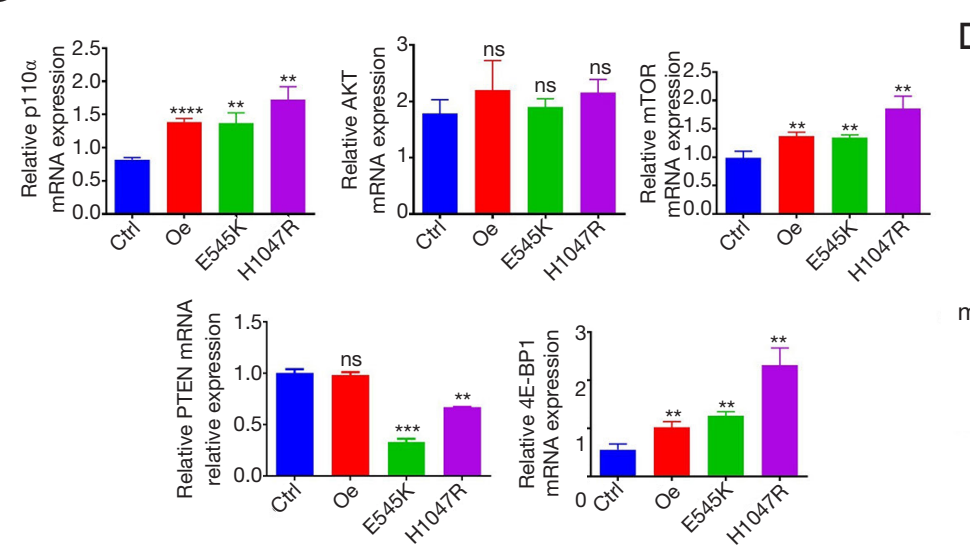

$E$

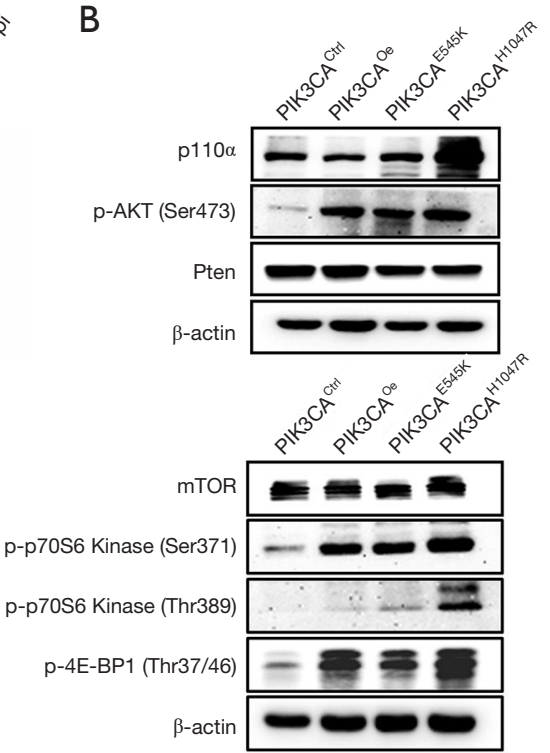

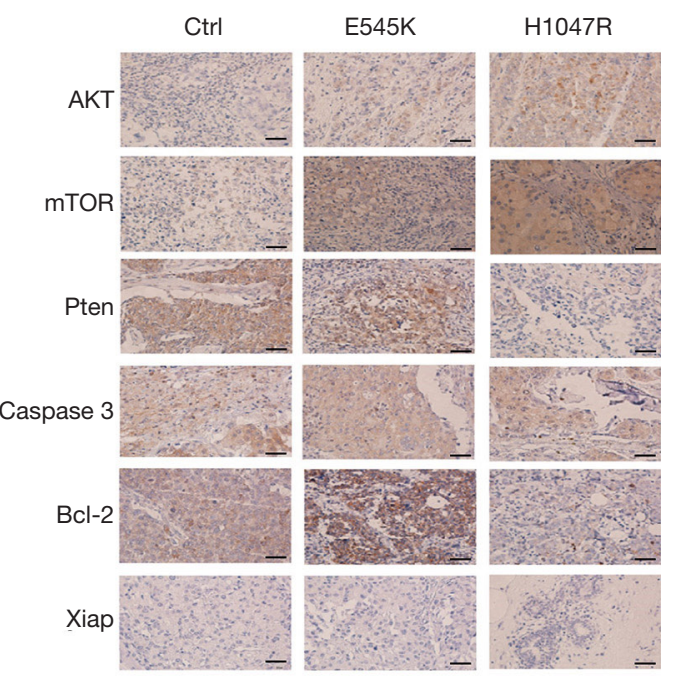

D

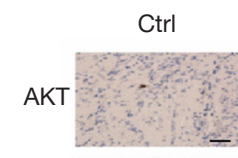

$\mathrm{Oe}$

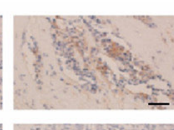

mTOR

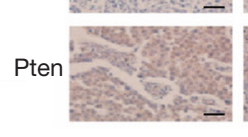

E545K

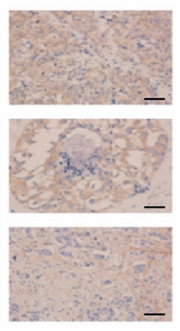

H1047R

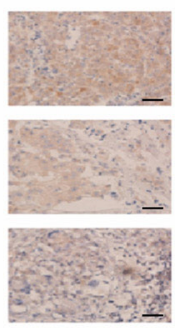

Figure 3 PIK3CA mutation activates PI3K/AKT/mTOR signaling pathway to resist chemotherapy in TNBC cells. (A) Western blot analysis was used to detect the expression levels of AKT, p-AKT, mTOR, and p-mTOR protein in MDA-MB-231 cell lines treated with or without epirubicin. (B) Western blot analysis was used to detect the expression levels of p110 $\alpha$, p-AKT, Pten, mTOR, p-p70S6 kinase, and $\mathrm{p}-4 \mathrm{E}-\mathrm{BP} 1$ protein in tumors from mice in each group treated with epirubicin. (C) Quantitative analysis of messenger RNA (p110 $\alpha$, AKT, mTOR, Pten, and 4E-BP1) was conducted by RT-qPCR. $n=3$. Data shown as mean \pm SD. Different conditions were compared using one-way ANOVA and Tukey's multiple comparisons test. ${ }^{* *}, \mathrm{P}<0.01$; ${ }^{* * *}, \mathrm{P}<0.001$; ${ }^{* * *}, \mathrm{P}<0.0001$; ns means no significance for $\mathrm{PIK} 3 \mathrm{CA}{ }^{\mathrm{Oe}}$, PIK3CA ${ }^{\mathrm{E} 545 \mathrm{~K}}, \mathrm{PIK} 3 \mathrm{CA}^{\mathrm{H} 1047 \mathrm{R}}$ vs. PIK3CA ${ }^{\text {ctrl }}$. (D) Immunohistochemistry was used to detect AKT, mTOR, and Pten proteins in tumor tissues from mice. Bar, $50 \mu \mathrm{m}$. (E) Immunohistochemistry was used to detect apoptosis-related proteins and proteins pertaining to the PI3K/AKT/ mTOR pathway in patients with TNBC. Bar, $50 \mu \mathrm{m}$.

between the groups (Figure 3E).

\section{Discussion}

PIK3CA is the second most commonly mutated gene in $\mathrm{BC}$ after P53 (24), which has been proved to be related to resistance to endocrine therapy in $\mathrm{HR}+\mathrm{BC}$ and to anti-HER2 therapy in HER2 + BC $(13,14)$. In HR+ BC,
PIK3CA mutation was reported to be responsible for the downstream alteration of cyclin $\mathrm{D} 1$ and $\mathrm{Rb}$ protein, which conferred resistance to fulvestrant (13). In HER2+ BC, tumors carrying PIK3CA mutations were inclined to be enriched with tumor-infiltrating lymphocytes, CD8, and FOXP3-positive cells, indicating the activation of the PI3K pathway and the weakening of the antibody-dependent cellmediated cytotoxicity of trastuzumab (25). Some studies 
Table 1 Comparison of patient clinicopathological characteristics between the PIK3CA mutation and PIK3CA wild-type groups

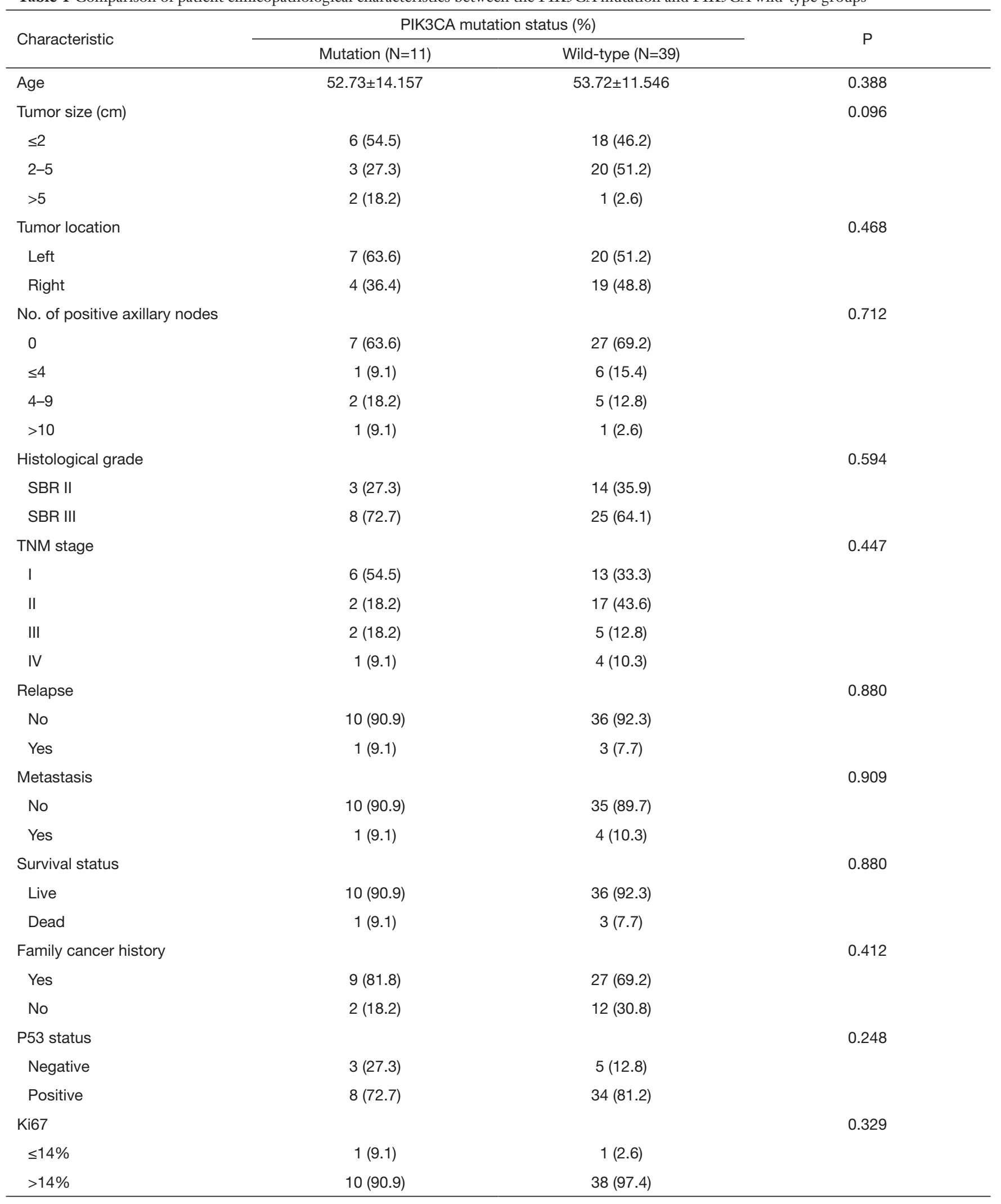


have reported NAC to have low pCR rates in patients with TNBC with PIK3CA mutation (19-21). Therefore, we supposed that mutations in the PIK3CA gene might be correlated to a negative response to chemotherapy, but the molecular mechanism remained unknown. In our study, we provided evidence that PIK3CA mutation in E545K or H1047R, conferred a more aggressive phenotype in TNBC cells. Importantly, we proved that PIK3CA mutation could lead to the constitutive activation of the PI3K/AKT/mTOR pathway and suppression of apoptosis, which contributed to chemotherapy resistance in TNBC.

Ghodsinia et al. reported that mutations in PIK3CA are mostly located in the kinase and helix regions and can enhance cell proliferation and survival (26). We constructed cell lines carrying two typical mutated hotspots, E545K (exon 9) and H1047R (exon 20), and PIK3CA gene overexpression. Our data revealed that mutations in $\mathrm{E} 545 \mathrm{~K}$ and $\mathrm{H} 1047 \mathrm{R}$ conferred a similar phenotype as overexpression of the PIK3CA gene in the processes of cell migration, proliferation, and apoptosis. Interestingly, the inhibitive effect of PIK3CA gene mutation on apoptosis was remarkable compared with its impact on proliferation in TNBC cells. Gain-of-function mutations in PIK3CA could activate several signaling pathways in cancers, most notably the PI3K/AKT pathway $(7,26)$; however, a previous study reported that there was not necessarily an association between PIK3CA mutation and downstream PI3K pathway activation (27). In the present study, we conducted western blot and immunochemistry assays in cells and chemotherapy-treated mice and observed higher expression levels of AKT, mTOR, p-4E-BP1, and p70S6K, but a lower expression of Pten protein in the PIK3 $3 \mathrm{CA}^{\mathrm{E} 545 \mathrm{~K}}$ and PIK3 $\mathrm{CA}^{\mathrm{H} 1047 \mathrm{R}}$ groups. These results revealed that the $\mathrm{PI} 3 \mathrm{~K} / \mathrm{AKT} / \mathrm{mTOR}$ pathway might play a significant role in chemotherapy resistance in TNBCs carrying mutations in the PIK3CA gene.

Notably, there were also differences between E545K and H1047R mutations in our study. For instance, among MDAMB-468 cells, those with PIK3CA ${ }^{\mathrm{H} 1047 \mathrm{R}}$ mutation exhibited significantly more aggressive migration ability than the control group, whereas those with PIK3 $\mathrm{CA}^{\mathrm{E} 545 \mathrm{~K}}$ mutation did not. After epirubicin therapy, the proportion of early apoptotic cells in the PIK3 $3 \mathrm{CA}^{\mathrm{E} 545 \mathrm{~K}}$ group decreased, whereas an increasing trend was seen in the PIK3 $\mathrm{CA}^{\mathrm{H} 1047 \mathrm{R}}$ group. In the immunohistochemical analysis of patients with TNBC, there was also a differential expression of proteins (Pten and $\mathrm{Bcl}-2$ ) in the PIK3 $3 \mathrm{CA}^{\mathrm{H} 1047 \mathrm{R}}$ and PIK3 $3 \mathrm{CA}^{\mathrm{E} 545 \mathrm{~K}}$ groups. Abramson et al. (28) reported that patients with BC with exon 9 mutation had a poorer prognosis than those with exon 20 mutation. Janku et al. (29) and Loi et al. (30) found that compared to patients with PIK3CA wild-type and E542K/E545Kmutant BC, those with H1047R mutation had a higher pCR after NAC, but no difference was observed in overall and progression-free survival (PFS). Jacot et al. (31) claimed that PIK3CA mutation in exon 9 was an independent prognostic factor in TNBC, while the mutation in exon 20 was not. Previous studies have reported the different channels affected by the 2 mutation hotspot regions. E545K oncogenic mutant was found to disrupt the inhibitory charge-charge interaction with the p85 N-terminal SH2 domain (32). However, the mutation in H1047R, located in the kinase region, upregulated the activation of downstream PI3K kinase proteins (33). Besides, Zhao et al. (34) showed that the gain of function induced by exon 9 mutation was independent of binding to the $\mathrm{p} 85$ subunit and required interaction with RAS-GTP, but this was not a necessity for exon 20 mutation. These differences might explain the differential phenotype and prognostic influence of mutations in exons 9 and 20.

Additionally, we collected the clinical data of 50 TNBC patients to explore the impact of PIK3CA mutation on clinicopathology and prognosis. The initial analysis demonstrated that PIK3CA mutation might be associated with relapse and death in patients with TNBC; however, there was no statistical difference. It is still debatable whether or not PIK3CA mutation brings about a negative prognosis in TNBC. Although some previous reports showed that patients harboring this genetic alteration had poorer clinical outcomes $(15,35,36)$, some authors have reported opposite results $(16,18)$. The reason for this discordance might be complex. Firstly, inconsistent samples, tumor tissue, or circulating free DNA in plasma were used to detect PIK3CA mutation in different studies, and the accuracy of detection methods might vary. Furthermore, PIK3CA mutation might result in different prognostic outcomes in metastatic and early TNBC. As reported by Mosele et al. (18), patients with metastatic TNBC with PIK3CA mutation tended to have better overall survival than those with PIK3CA wild-type TNBC (24 vs. 14 months, $\mathrm{P}=0.03$ ), partly because of the high distribution of patients with $\mathrm{HR}+$ primary tumors, which belonged to a less aggressive subtype of BC. Approximately $6 \%$ of patients with HR-primary tumors and $36 \%$ of patients with $\mathrm{HR}+$ primary tumors present with PIK3CA mutation in metastatic TNBC. Therefore, it is necessary to include patients with the same TNBC stage and chemotherapy 
regimens in future studies. Moreover, TNBC has been proved to be a heterogeneous tumor that can be classified into 4 or more subtypes $(37,38)$. Lehmann et al. (39) reported that mutations in PIK3CA occurred more frequently in a subset of androgen receptor-positive (AR+) TNBC tumors, which were less likely to benefit from chemotherapy. Therefore, the different prognostic outcomes reported for PIK3CA mutation in TNBC could also be attributed to its heterogeneity. In a further study, subgroup analyses of patients with TNBC are necessary.

Currently, the standard care for TNBC still comprises chemotherapy combinations and is associated with excellent clinical response rates. Nonetheless, drug resistance can still constitute a challenge for clinicians. Our study proved there was a crucial relevance between PIK3CA mutation and chemotherapy resistance, suggesting that PIK3CA mutation could potentially serve as a predictive biomarker in patients receiving chemotherapy for TNBC. We suppose that PIK3CA mutations can be routinely detected in patients with TNBC to estimate their chemotherapy response. Jiang et al. (37) reported that PIK3CA mutations and copynumber gains of chromosome $22 \mathrm{q} 11$ were more frequent in a Chinese cohort than in The Cancer Genome Atlas. In particular, about $70 \%$ of luminal androgen receptortype tumors showed somatic mutations in the PI3K/ AKT/mTOR pathway. Our study indicated that PIK3CA mutation triggered the PI3K/AKT/mTOR signaling's sustained activation to inhibit apoptosis in TNBC. We hypothesize that agents targeting PIK3CA mutation (i.e., alpha-specific PI3K inhibitors) and other proteins in the downstream pathway might enhance chemotherapeutic sensitivity and accelerate tumor cell apoptosis. Several PI3K inhibitors have been assessed in combination with endocrine therapy in HR+/HER2- BC and have achieved an outstanding response (40). Alpelisib, an alpha-specific PI3 K inhibitor, was evaluated in phase III SOLAR-1 study. The study results demonstrated that alpelisib plus fulvestrant improved PFS compared with fulvestrant (11.0 vs. 5.7 months, HR $0.65,95 \%$ CI: 0.50 to $0.85, \mathrm{P}<0.001)$ in a cohort of patients with HR+/HER2- metastatic BC with PIK3CA mutation (41). However, clinical trials of PI3K/ AKT/mTOR pathway inhibitors aiming to treat TNBC are limited, and many ongoing trials have yet to report their results (23). Buparlisib, a PI3K inhibitor, was tested in the BELLE-4 trial, which concluded that patients with TNBC exhibited a poorer PFS with buparlisib paclitaxel than with paclitaxel monotherapy (5.5 vs. 9.3 months, HR 1.86, 95\% CI: 0.91-3.79). Patients with mutations in the PIK3CA gene also failed to benefit from the combination of buparlisib and paclitaxel in terms of prognosis (HR 1.17, 95\% CI: 0.63-2.17) (42). Lehmann et al. (39) demonstrated that PIK3CA mutations in AR+ TNBC conferred sensitivity to the combination of PI3K and AR inhibitors both in vivo and in vitro. In the subsequent TBCRC $032 \mathrm{IB} / \mathrm{II}$ multicenter study (43), Lehmann et al. observed the efficacy of $\mathrm{AR}$ antagonist and $\mathrm{PI} 3 \mathrm{~K}$ inhibitor in patients with $\mathrm{AR}+$ metastatic TNBC. Patients with PIK3CA mutation had a higher clinical benefit rate $(42.9 \%$ vs. $28.6 \%, \mathrm{P}=1.00)$ and improved PFS (2.7 vs. 2.0 months, $\mathrm{P}=0.83$ ) compared to patients with PIK3CA wild-type, although the difference was not significant. Recently, several clinical trials have assessed AKT inhibitors in the treatment of TNBC. For instance, the PAKT trial showed that capivasertib, an AKT inhibitor, brought an increase in PFS, from 4.2 months with paclitaxel plus placebo $v s .5 .9$ months with capivasertib plus paclitaxel (HR 0.75, 95\% CI: 0.52-1.08, $\mathrm{P}=0.06$ ). Importantly, pre-planned analysis of PIK3CA/AKT1/Ptenaltered tumors reported prolonged PFS in the capivasertib group compared with the placebo group $(9.3 v s .3 .7$ months, HR $0.30,95 \%$ CI: $0.11-0.79, \mathrm{P}=0.01$ ) (44). It appears that AKT inhibitors might be more efficient than PI3K inhibitors in treating PIK3CA-aberrant TNBC tumors. Accordingly, more randomized controlled trials exploring PI3K pathway inhibition in TNBC are required in the future.

Some potential limitations exist in our study. Although the fundamental conclusion was not undermined, the dose of epirubicin injected into the mice might have been slightly too low since the mice's tumor volume maintained an increasing trend after treatment. Also, the overall number of patients with TNBC included in our study was small, resulting in a deviation in the prognostic analysis. We are currently recruiting more TNBC patients for verification, and relevant results will be reported in our future study.

In conclusion, PIK3CA mutation activates the PI3K/ AKT/mTOR signaling pathway and inhibits apoptosis in TNBC cells, contributing to the resistance to chemotherapy in TNBC. More importantly, PIK3CA mutation is a potential monitoring biomarker, and patients with TNBC who carry this mutation may benefit from PI3K pathway inhibitors.

\section{Acknowledgments}

Funding: This work was supported by the National Natural Science Foundation (grant number: 81372386). 


\section{Footnote}

Reporting Checklist: The authors have completed the ARRIVE reporting checklist. Available at http://dx.doi. org/10.21037/atm-21-698

Data Sharing Statement: Available at http://dx.doi. org/10.21037/atm-21-698

Conflicts of Interest: All authors have completed the ICMJE uniform disclosure form (available at http://dx.doi. org/10.21037/atm-21-698). The authors have no conflicts of interest to declare.

Ethical Statement: The authors are accountable for all aspects of the work in ensuring that questions related to the accuracy or integrity of any part of the work are appropriately investigated and resolved. The study was conducted in accordance with the Declaration of Helsinki (as revised in 2013). The study was approved by Ethics Committee of Chinese PLA General Hospital (No. S2016-023-01) and informed consent was taken from all individual participants. Animal experiments were performed under a project license (No. S2016-023-01) granted by Ethics Committee of Chinese PLA General Hospital, in compliance with NIH guidelines for the care and use of animals.

Open Access Statement: This is an Open Access article distributed in accordance with the Creative Commons Attribution-NonCommercial-NoDerivs 4.0 International License (CC BY-NC-ND 4.0), which permits the noncommercial replication and distribution of the article with the strict proviso that no changes or edits are made and the original work is properly cited (including links to both the formal publication through the relevant DOI and the license). See: https://creativecommons.org/licenses/by-nc-nd/4.0/.

\section{References}

1. Bray F, Ferlay J, Soerjomataram I, et al. Global cancer statistics 2018: GLOBOCAN estimates of incidence and mortality worldwide for 36 cancers in 185 countries. CA Cancer J Clin 2018;68:394-424.

2. Foulkes WD, Smith IE, Reis-Filho JS. Triple-negative breast cancer. N Engl J Med 2010;363:1938-48.

3. Cain H, Macpherson IR, Beresford M, et al. Neoadjuvant Therapy in Early Breast Cancer: Treatment Considerations and Common Debates in Practice. Clin Oncol (R Coll Radiol) 2017;29:642-52.

4. Eisenhauer EA, Therasse P, Bogaerts J, et al. New response evaluation criteria in solid tumours: revised RECIST guideline (version 1.1). Eur J Cancer 2009;45:228-47.

5. Nedeljković M, Damjanović A. Mechanisms of chemotherapy resistance in triple-negative breast cancerhow we can rise to the challenge. Cells 2019;8:957.

6. Katso R, Okkenhaug K, Ahmadi K, et al. Cellular function of phosphoinositide 3-kinases: implications for development, homeostasis, and cancer. Annu Rev Cell Dev Biol 2001;17:615-75.

7. Samuels Y, Diaz LA Jr, Schmidt-Kittler O, et al. Mutant PIK3CA promotes cell growth and invasion of human cancer cells. Cancer Cell 2005;7:561-73.

8. Zhao L, Vogt PK. Class I PI3K in oncogenic cellular transformation. Oncogene 2008;27:5486-96.

9. Saal LH, Holm K, Maurer M, et al. PIK3CA mutations correlate with hormone receptors, node metastasis, and ERBB2, and are mutually exclusive with PTEN loss in human breast carcinoma. Cancer Res 2005;65:2554-9.

10. Miricescu D, Totan A, Stanescu-Spinu II, et al. PI3K/ AKT/mTOR Signaling Pathway in Breast Cancer: From Molecular Landscape to Clinical Aspects. Int J Mol Sci 2020;22:173.

11. Karakas B, Bachman KE, Park BH. Mutation of the PIK3CA oncogene in human cancers. Br J Cancer 2006;94:455-9.

12. Martínez-Sáez O, Chic N, Pascual T, et al. Frequency and spectrum of PIK3CA somatic mutations in breast cancer. Breast Cancer Res 2020;22:45.

13. Huang D, Tang L, Yang F, et al. PIK3CA mutations contribute to fulvestrant resistance in ER-positive breast cancer. Am J Transl Res 2019;11:6055-65.

14. Rimawi MF, De Angelis C, Contreras A, et al. Low PTEN levels and PIK3CA mutations predict resistance to neoadjuvant lapatinib and trastuzumab without chemotherapy in patients with HER2 over-expressing breast cancer. Breast Cancer Res Treat 2018;167:731-40.

15. Wang J, Zhu X, Xu X, et al. PIK3CA mutations and downstream effector $\mathrm{p}-\mathrm{mTOR}$ expression: implication for prognostic factors and therapeutic targets in triple negative breast cancer. Int J Clin Exp Pathol 2017;10:7682-91.

16. Takeshita T, Yamamoto Y, Yamamoto-Ibusuki M, et al. Prognostic role of PIK3CA mutations of cell-free DNA in early-stage triple negative breast cancer. Cancer Sci 2015;106:1582-9.

17. González-Martínez S, Perez-Mies B, Carretero-Barrio I, 
et al. Molecular features of metaplastic breast carcinoma: an infrequent subtype of triple negative breast carcinoma. Cancers (Basel) 2020;12:1832.

18. Mosele F, Stefanovska B, Lusque A, et al. Outcome and molecular landscape of patients with PIK3CA-mutated metastatic breast cancer. Ann Oncol 2020;31:377-86.

19. Guo S, Loibl S, von Minckwitz G, et al. PIK3CA H1047R Mutation Associated with a Lower Pathological Complete Response Rate in Triple-Negative Breast Cancer Patients Treated with Anthracycline-Taxane-Based Neoadjuvant Chemotherapy. Cancer Res Treat 2020;52:689-96.

20. Marra A, Trapani D, Viale G, et al. Practical classification of triple-negative breast cancer: intratumoral heterogeneity, mechanisms of drug resistance, and novel therapies. NPJ Breast Cancer 2020;6:54.

21. Di Cosimo S, Appierto V, Silvestri M, et al. Targetedgene sequencing to catch triple negative breast cancer heterogeneity before and after neoadjuvant chemotherapy. Cancers 2019;11:1753.

22. Khasraw M, Bell R, Dang C. Epirubicin: Is it like doxorubicin in breast cancer? A clinical review. Breast 2012;21:142-9.

23. Pascual J, Turner NC. Targeting the PI3-kinase pathway in triple-negative breast cancer. Annals Of Oncology 2019;30:1051-60.

24. Cheng J, Ding X, Xu S, et al. Gene expression profiling identified TP53(Mut)PIK3CA(Wild) as a potential biomarker for patients with triple-negative breast cancer treated with immune checkpoint inhibitors. Oncology Letters 2020;19:2817-24.

25. Guarneri V, Dieci MV, Bisagni G, et al. PIK3CA Mutation in the ShortHER Randomized Adjuvant Trial for Patients with Early HER2(+) Breast Cancer: Association with Prognosis and Integration with PAM50 Subtype. Clin Cancer Res 2020;26:5843-51.

26. Ghodsinia AA, Lego JMT, Garcia RL. MutationAssociated Phenotypic Heterogeneity in Novel and Canonical PIK3CA Helical and Kinase Domain Mutants. Cells 2020;9:1116.

27. Beelen K, Opdam M, Severson TM, et al. PIK3CA mutations, phosphatase and tensin homolog, human epidermal growth factor receptor 2, and insulin-like growth factor 1 receptor and adjuvant tamoxifen resistance in postmenopausal breast cancer patients. Breast Cancer Res 2014;16:R13.

28. Abramson VG, Lloyd MC, Ballinger T, et al. Characterization of breast cancers with PI3K mutations in an academic practice setting using $\mathrm{SNaPshot}$ profiling.
Breast Cancer Res Treat 2014;145:389-99.

29. Janku F, Wheler JJ, Naing A, et al. PIK3CA mutations in advanced cancers: characteristics and outcomes. Oncotarget 2012;3:1566-75.

30. Loi S, Haibe-Kains B, Majjaj S, et al. PIK3CA mutations associated with gene signature of low mTORC1 signaling and better outcomes in estrogen receptor-positive breast cancer. Proc Natl Acad Sci U S A 2010;107:10208-13.

31. Jacot W, Mollevi C, Fina F, et al. High EGFR protein expression and exon 9 PIK3CA mutations are independent prognostic factors in triple negative breast cancers. BMC Cancer 2015;15:986.

32. Miled N, Yan Y, Hon WC, et al. Mechanism of two classes of cancer mutations in the phosphoinositide 3-kinase catalytic subunit. Science 2007;317:239-42.

33. Kang S, Bader AG, Zhao L, et al. Mutated PI 3-kinases - Cancer targets on a silver platter. Cell Cycle 2005;4:578-81.

34. Zhao L, Vogt PK. Helical domain and kinase domain mutations in p110 alpha of phosphatidylinositol 3-kinase induce gain of function by different mechanisms. Proc Natl Acad Sci U S A 2008;105:2652-7.

35. Philipovskiy A, Dwivedi AK, Gamez R, et al. Association between tumor mutation profile and clinical outcomes among Hispanic Latina women with triple-negative breast cancer. PLoS One 2020;15:e0238262.

36. Chen X, Guo Y, Ouyang T, et al. Co-mutation of TP53 and PIK3CA in residual disease after neoadjuvant chemotherapy is associated with poor survival in breast cancer. J Cancer Res Clin Oncol 2019;145:1235-42.

37. Jiang YZ, Ma D, Suo C, et al. Genomic and transcriptomic landscape of triple-negative breast cancers: subtypes and treatment strategies. Cancer Cell 2019;35:428-440.e5.

38. Lehmann BD, Bauer JA, Chen X, et al. Identification of human triple-negative breast cancer subtypes and preclinical models for selection of targeted therapies. J Clin Invest 2011;121:2750-67.

39. Lehmann BD, Bauer JA, Schafer JM, et al. PIK3CA mutations in androgen receptor-positive triple negative breast cancer confer sensitivity to the combination of $\mathrm{PI} 3 \mathrm{~K}$ and androgen receptor inhibitors. Breast Cancer Res 2014;16:406.

40. Nagaraj G, Ma CX. Clinical Challenges in the Management of Hormone Receptor-Positive, Human Epidermal Growth Factor Receptor 2-Negative Metastatic Breast Cancer: A Literature Review. Adv Ther 2021;38:109-36.

41. André F, Ciruelos E, Rubovszky G, et al. Alpelisib for 
PIK3CA-Mutated, Hormone Receptor-Positive Advanced Breast Cancer. N Engl J Med 2019;380:1929-40.

42. Martín M, Chan A, Dirix L, et al. A randomized adaptive phase II/III study of buparlisib, a pan-class I PI3K inhibitor, combined with paclitaxel for the treatment of HER2 - advanced breast cancer (BELLE-4). Ann Oncol 2017;28:313-20.

43. Lehmann BD, Abramson VG, Sanders ME, et al. TBCRC 032 IB/II Multicenter Study: Molecular Insights to AR Antagonist and PI3K Inhibitor Efficacy in Patients with

Cite this article as: $\mathrm{Hu} \mathrm{H}$, Zhu J, Zhong $\mathrm{Y}$, Geng R, Ji Y, Guan Q, Hong C, Wei Y, Min N, Qi A, Zhang Y, Li X. PIK3CA mutation confers resistance to chemotherapy in triplenegative breast cancer by inhibiting apoptosis and activating the PI3K/AKT/mTOR signaling pathway. Ann Transl Med 2021;9(5):410. doi: 10.21037/atm-21-698
$\mathrm{AR}(+)$ Metastatic Triple-Negative Breast Cancer. Clin Cancer Res 2020;26:2111-23.

44. Schmid P, Abraham J, Chan S, et al. AZD5363 plus paclitaxel versus placebo plus paclitaxel as first-line therapy for metastatic triple-negative breast cancer (PAKT): A randomised, double-blind, placebo-controlled, phase II trial. J Clin Oncol 2018;36:abstr 1007.

(English Language Editors: J. Reynolds and J. Chapnick) 


\section{Supplementary}

Table S1 The sequences of the specific primers for PIK3CA ${ }^{\mathrm{Oe}}, \mathrm{PIK} \mathrm{CA}^{\mathrm{E} 545 \mathrm{~K}}$, and PIK3CA ${ }^{\mathrm{H} 1047 \mathrm{R}}$ in plasmids

\begin{tabular}{ll}
\hline Primer & Sequence (5' to $\left.3^{\prime}\right)$ \\
\hline PIK3CA $^{\text {oe }}$ & Forward: GAGGATCCCCGGGTACCGGTCGCCACCATGCCTCCACGACCATCATCAGGTGAAC \\
& Reverse: TCCTTGTAGTCCATACCGTTCAATGCATGCTGTTTAATTGTGTG \\
& Forward: GAGGATCCCCGGGTACCGGTCGCCACCATGCCTCCACGACCATCATCAGGTGAAC \\
& Reverse: TCCTTGTAGTCCATACCGTTCAATGCATGCTGTTTAATTGTGG \\
& Forward: GAGGATCCCCGGGTACCGGTCGCCACCATGCCTCCACGACCATCATCAGGTG \\
& Reverse: TCCTTGTAGTCCATACCGTTCAATGCATGCTGTTTAATTGTGTGGAAGATCCAATCCATTTTTGTTG
\end{tabular}

A
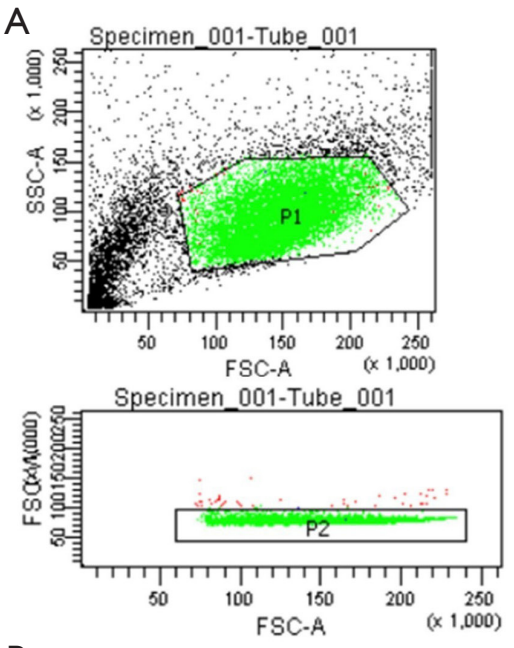

B
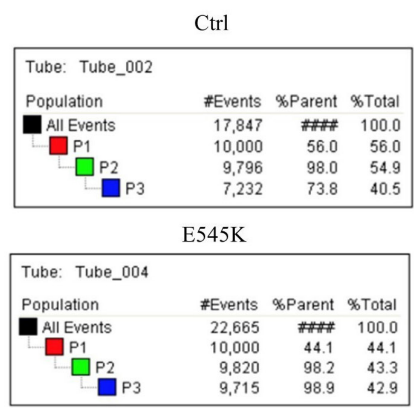

C

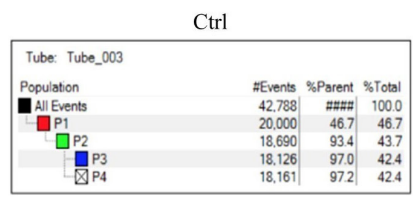

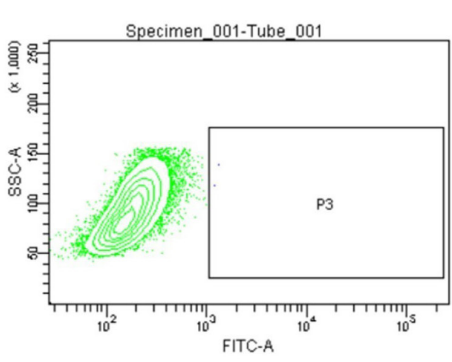

D
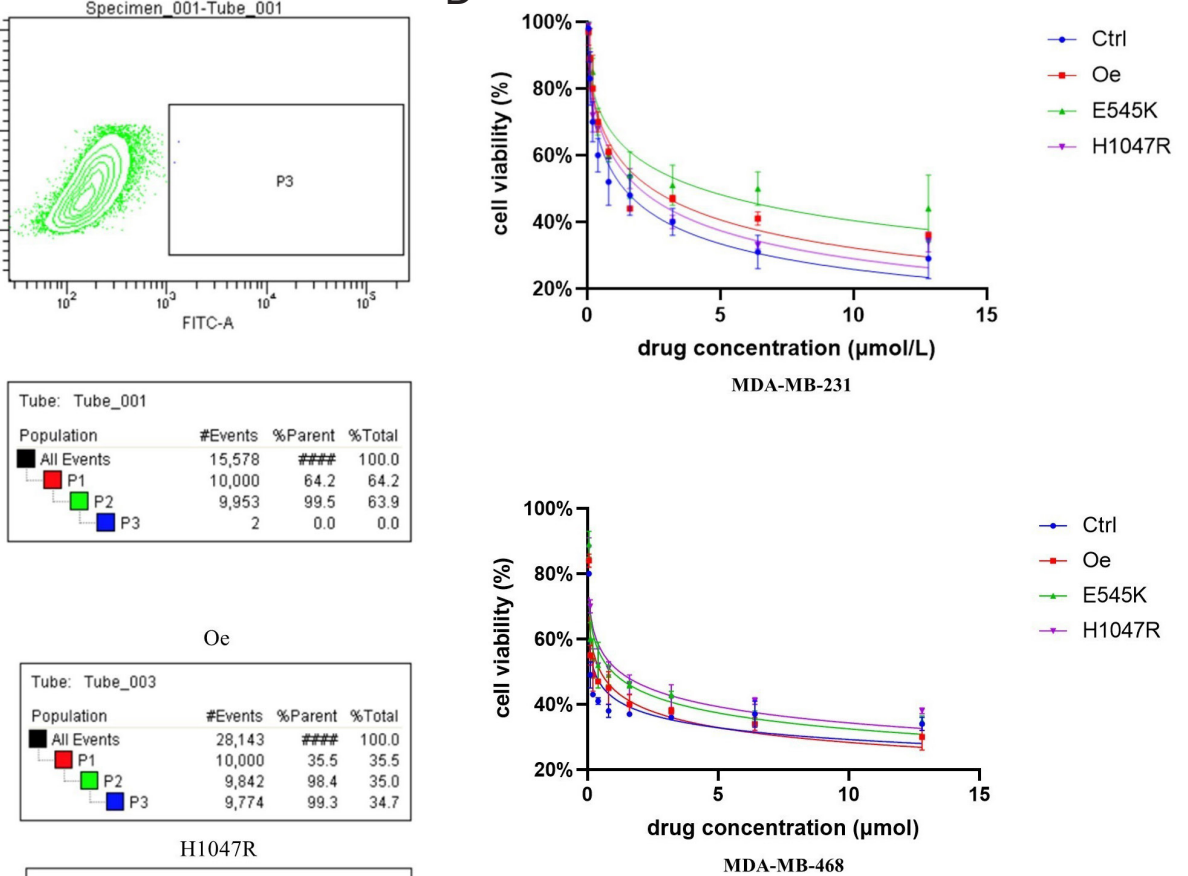

$\rightarrow$ Ctrl

$\rightarrow \mathrm{Oe}$

$\rightarrow$ E545K

$\rightarrow \mathrm{H} 1047 \mathrm{R}$
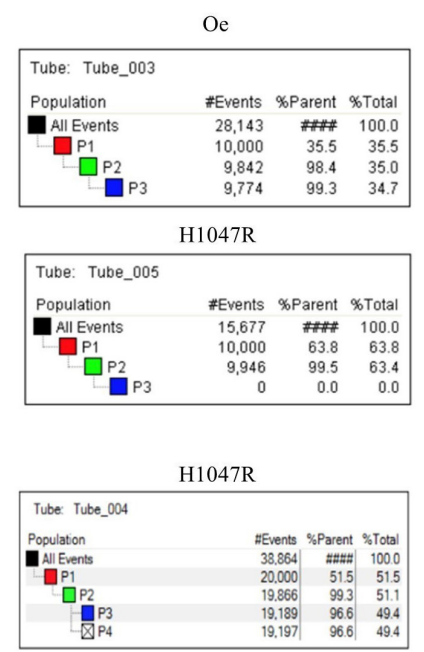

Figure S1 Isolation of single cell populations and $\mathrm{IC}_{50}$ analysis for epirubicin. (A) The procedure for isolating and characterizing transfected cells (e.g., MDA-MB-231, wild-type). The P3 section represents the cells isolated. In this figure, few cells can be seen in the P3 section, since wild-type cells did not carry the GFP protein. (B) Initial isolation of transfected populations of MDA-MB-231 cells. Proportion of cells carrying GFP: $73.8 \%$ for PIK3CA ${ }^{\text {ctrl }}, 99.3 \%$ for PIK3CA ${ }^{\mathrm{Oe}}, 98.9 \%$ for PIK3CA ${ }^{\mathrm{E} 545 \mathrm{~K}}$, and $0 \%$ for PIK3CA ${ }^{\mathrm{H} 1047 \mathrm{R}}$. $(\mathrm{C})$ Second isolation of PIK3CA ${ }^{\text {ctrl }}$ and PIK3CA ${ }^{\mathrm{H} 1047 \mathrm{R}}$ MDA-MB-231 cells for their low proportions in initial isolation. Proportion of cells Vcarrying GFP: $97.2 \%$ for PIK3 $\mathrm{CA}^{\text {ctrl }}$ and $96.6 \%$ for PIK3CA ${ }^{\mathrm{H} 1047 \mathrm{R}}$. (D) The drug susceptivity of each cell line was determined by cellular drug resistance assay. Cell viability wase measured under different concentrations of epirubicin, and each $\mathrm{IC}_{50}$ value is listed in Table S2. 
Table S2 The $\mathrm{IC}_{50}$ value for epirubicin in each cell group $(\mu \mathrm{mol} / \mathrm{L})$

\begin{tabular}{lcccc}
\hline Cell lines & PIK3CA $^{\text {Crrl }}$ & PIK3CA $^{\text {Oe }}$ & PIK3CA $^{\text {E545K }}$ & PIK3CA $^{\text {H1047R }}$ \\
\hline MDA-MB-231 & 1.38 & 2.43 & 4.23 & 1.97 \\
MDA-MB-468 & 0.27 & 0.50 & 0.95 & 1.23 \\
\hline
\end{tabular}

Table S3 Information of primary antibodies used in Western blot

\begin{tabular}{lccc}
\hline Antibody & Dilution & Catalogue number & Manufacturer \\
\hline PI3 Kinase p110 & $1: 1,000$ & 4249 & CST (Cell Signaling Technology) \\
AKT (pan) & $1: 2,000$ & 2920 & CST \\
p-AKT (Ser473) & $1: 2,000$ & 4060 & CST \\
p-AKT (Thr308) & $1: 1,000$ & 13038 & CST \\
p-mTOR (Ser2448) & $1: 1,000$ & 5536 & CST \\
p-p70 S6 Kinase (Thr389) & $1: 1,000$ & 9206 & CST \\
p-p70 S6 Kinase (Ser 371) & $1: 1,000$ & 9208 & CST \\
p-4E-BP1 (Thr37/46) & $1: 1,000$ & 2855 & CST \\
Xiap & $1: 1,000$ & 14334 & CST \\
Bcl-2 & $1: 1,000$ & 3498 & CST \\
$\beta$-actin & $1: 200$ & 47778 & Santa Cruz \\
mTOR & $1: 200$ & 517464 & Santa Cruz \\
Pten & $1: 200$ & 7974 & Santa Cruz \\
\hline
\end{tabular}

Table S4 The sequences of the specific primer for mTOR, Pten, PIK3CA, AKT, EIF4EBP 1 and $\beta$-actin in RT-qPCR

\begin{tabular}{ll}
\hline Primer & Sequence (5' to ${ }^{\prime}$ ) \\
\hline mTOR & Forward: GCCGCGCGAATATTAAAGGAA \\
& Reverse: TGGTTTCCTCATTCCGGCTC \\
Pten & Forward: ACCCACCACAGCTAGAACTT \\
& Reverse: GGGAATAGTTACTCCCTTTTTGT \\
PIK3CA & Forward: TTACCCTCTTCTGCCGGAGG \\
& Reverse: AAGTGGATGCCCCACAGTTC \\
AKT & Forward: GAAGGACGGGAGCAGGC \\
& Reverse: CTCACGCGCTCCTCTCAG \\
EIF4EBP1 & Forward: GGAGTGTCGGAACTCACCTG \\
& Reverse: ACACGATGGCTGGTGCTTTA \\
B-actin & Forward: CCGTTCCGAAAGTTGCTTTT \\
& Reverse: ATCATCCATGGTGAGCTGGC \\
\hline
\end{tabular}

